Neven Grubišić, Ph.D.

Siniša Vilke, Ph.D.

Mate Barić, M.Eng.

University of Rijeka, Faculty of Maritime Studies, Studentska 2, 51000 Rijeka

\title{
A Contribution to Berth Allocation Problem Solution with Draft Restrictions
}

\begin{abstract}
Models for berth assignments help to solve logistic problems in container terminals and are important decision making tools. This is particularly so where, because of the system complexity and vessels arrival rate, problems cannot be solved empirically. Another issue concerns potential infrastructure and equipment shortcomings, where high utilization of the existing system components is required. In this paper, the authors focus on draft or depth restrictions that may occur alongside a quay. The existing researches in this field are surveyed and the model for berth allocation optimization is upgraded to fulfil draft restrictions. The model is tested in the environment both with and without sea-depth limitation alongside a quay. For validation purposes, random vessels arrivals are generated together with their technical particulars.
\end{abstract}

Key words: berth allocation problem, draft restriction, container terminal optimization, port logistics

\section{Introduction}

The Berth Allocation Problem (BAP) is one of the well-known tactical logistic problems in the optimization of the container terminals transport process. The problem is how to find an optimal berth assignment to vessels and to adjust vessel arrivals to preselected time windows. The objective is to maximize berth capacity and to minimize waiting time for vessels in port.

It could be generally said of many ports that conventional berthing schedule means vessels are docking according to their time of arrival. That is first come, first serviced. In container transport, however, vessels arrival schedule should be necessarily adopted in advance. On the terminal side, it is important for the quay and crane capacity to be utilized and for the overall terminal performance to be improved. On the shipping side, it is important for the berthing and servicing schedule to be accurate to the maximum extent and for the voyage planning schedule to be adjusted with the port service avail- 
ability. Therefore, optimization of schedule and vessels arrival is necessary in order for the required time windows to be matched.

There are two basic types of the BAP problem in the present research papers: the problem with fixed or discrete berths (BAPD) and the problem with continuous berths (BAPC), where berth length is not fixed. In discrete berths, a quay layout is divided into segments of fixed length. Each vessel occupies a predetermined berth position. In continuous berths, the position of a vessel alongside the quay is not fixed by berth number but may vary in dependence on the vessel length. That means that a ship occupies a part of the quay or the pier corresponding to its length.

The first authors to have published papers related to the discrete berth problem were Imai et al. [6] and Nishimura et al. [12]. The objective of optimization was minimization of the total ship service time at port and the earliest time of berth availability. Cordeau et al. [2] placed the optimization objective from the terminal operator view, with the objective to minimize the idle time between two consecutive vessels arrivals. A research concerning continuous berth layout was carried out by Lim [10]. The objective was to cut spaces between vessels to maximize the quay capacity. Actually, the problem was transformed into the well-known 2D-packing problem.

Another interesting issue is to put various attributes into the objective function according to terminal business strategy, technical or organizational limitations. Thereby, Kim and Moon [9] included the position preference attribute into the model. Deviations from the preferred position may increase the distance for container transhipment between a quay and the storage area and should be avoided. On the other hand, Guan and Cheung [3] included the priority coefficient into the model, which vary depending on vessel features or shipping company. With the introduction of the priority coefficient, vessels are not treated equally, but those with higher priority are less likely to wait for a free berth or free time windows. However, the interest point is that vessels are divided into groups based on their estimated time of arrival. Division has a practical meaning because it is difficult for the time of arrival to be predicted with complete accuracy several days in advance. Instead, the periods of time or time windows have to be determined in order for vessels to be able to reach the targeted time windows.

Where public ports are concerned, no priority rule should apply. This principle was represented by Imai et al. [5], [7], [8], where the so called terminals in the multi-user environment were dealt with. Those terminals served vessels of various sizes which belonged to different shipping companies without any preferable docking location available at the terminal. The position alongside quay depends on technical attributes of the terminal subsystems rather than on particular shipping companies.

A different approach has been shown by Moorthy and Teo [11], based on the optimization depending on cargo quantities to be loaded or discharged. They assume that vessels with larger cargo quantities should be granted a higher berth priority than those with lesser ones. A special feature of this work is that the proposed optimization is based on the domestic berth criteria. The so-called domestic berth will be granted to the same company whenever possible. That is connected with the transport cost 
for shifting and relocating containers grouped into the yard block at the terminal and prepared for loading onboard.

In this paper, the berth allocation problem with a hybrid berths layout is considered in relation to technical limitations, particularly depth restrictions. Depth constraint is one of the common factors affecting the decision to assign a berth to a vessel alongside the quay. If a vessel's draft is beyond the permitted level, then it is not possible for the vessel to be accommodated. In that case, such ships could be redirected to berths where depth is not a limiting factor, if available. A similar approach to this one can be found in [13], where water depth and tidal fluctuations are used as attributes. However, the authors have only considered BAP with fixed berths layout.

The objective of the model here presented is to optimize the berth schedule alongside the quay, taking into consideration restrictions in vessels draft, in order for vessels total service time at port to be minimized. Two different models are compared: with and without depth constraints in order to get the difference in berth layout and to compare the results of optimization. The structure of the paper is as follows: In section 2, the problem scope and the optimization methodology are described; section 3 specifies model developments; section 4 is about data generation and selection, while in section 5 optimization results are presented and analyzed.

\section{Methodology}

There are two main dimensions in the BAP problem formulation: vessel's total time spent at port and the space thereby occupied. Vessel's total time at port includes: the time between vessel's arrival at the pilot station and her berthing time (including the period spent at the anchorage), preparation time for cargo operation, time for handling operation, clearance time needed to prepare a vessel for departure and the departure time. The distribution of time periods during vessel's stay within the port area is shown in Fig.1. Point $t_{1}$ represents the time of vessel's arrival at the port area; $t_{2}$ is the starting time of vessel approaching the terminal berths; $t_{3}$ is berthing time; $t_{4}$ handling start time; $t_{5}$ handling finish time. During $t_{2}-t_{1}$ a vessel may be in the stand-by position or may be anchored. The time $t_{4}-t_{3}$ is reserved for the preparation of handling operations, and time $t_{6}-t_{5}$ is the clearance time required by a vessel to get prepared for departure after the completion of cargo operations. Finally, $t_{7}$ is the time a vessel leaves the port area. 


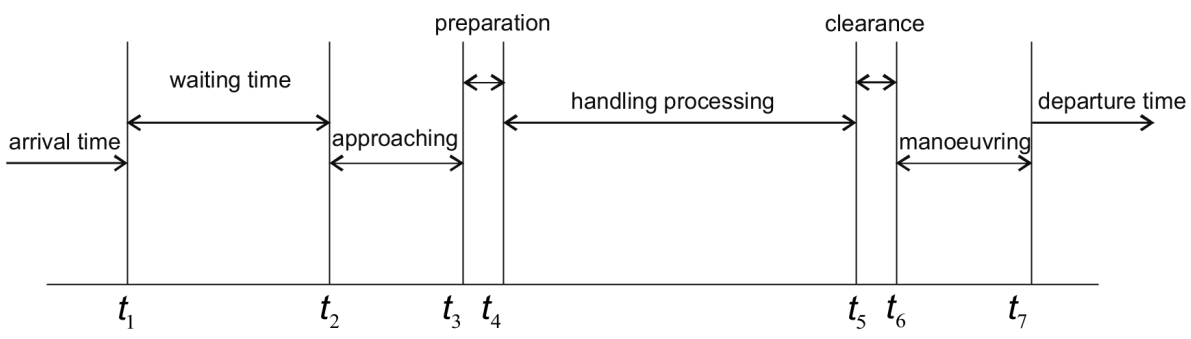

Figure 1: Distribution of vessel's time spent at port

Formulation of BAP depends largely on processing time assumptions. The duration of cargo operations is a separate optimization problem and depends strongly on cargo distribution onboard, on availability and productivity of quay cranes and on container demand. Considering the processing time assumption, according to Meisel, the BAP problem may be classified in four categories [14]:

- processing time is fixed and unchangeable

- processing time depends on berth allocation

- processing time depends on the number of cranes allocated to the vessel

- processing time depends on the quay crane schedule

The last two options are outside the scope of this paper. Where just the BAP solution is considered, the first option may be acceptable. Therefore, this approach is followed in the model development. The duration of the handling process is a fixed and constant parameter. It contains the cargo handling operation, preparation and clearance time. The approaching and manoeuvring times are not integrated into the model as they do not affect the optimization process ${ }^{1}$. Apart from the processing time, the estimated time of arrival (ETA) should be necessarily known for each vessel in the planning horizon. The estimated time of departure (ETD) depends on optimization results and it represents the sum of the arrival time, waiting time for free berth and processing time at berth.

The BAP problem may be represented graphically (Fig.2). The $x$-axis represents a time windows and the $y$-axis the length of the quay with berth segments. A rectangular shape actually represents the ship with the position in diagram determined by the assigned space-time windows.

$1 \quad$ The availability of pilots and tugs may affect vessels readiness for the maneuvering startup and thereby her berthing or departure time. However, the issue is beyond the scope of this research. 


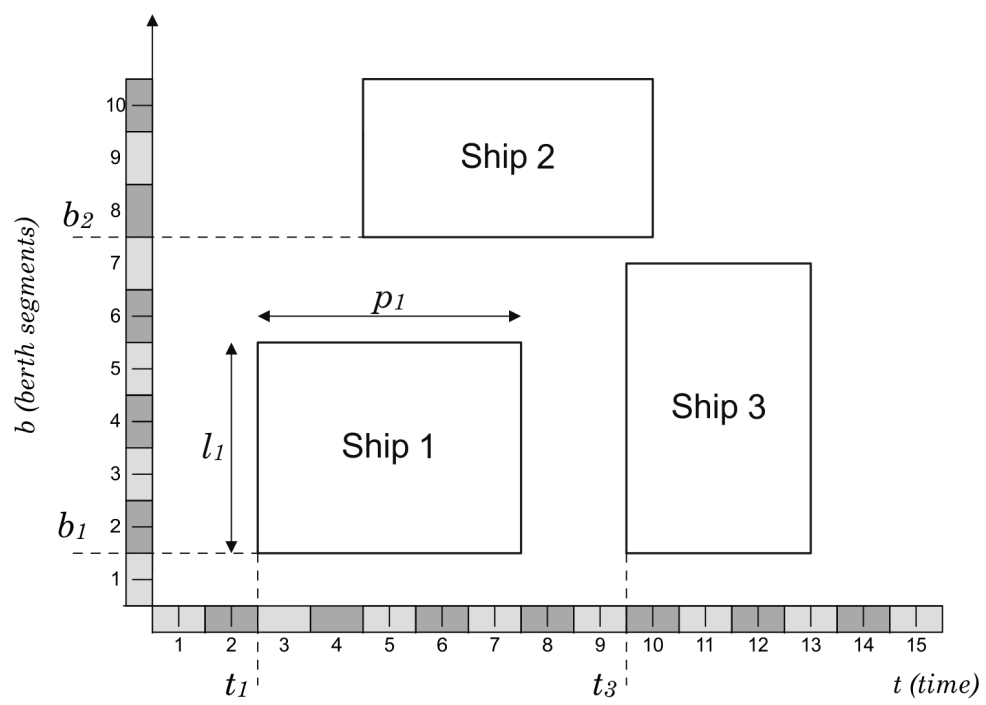

Figure 2: Graphical representation of the Berth Allocation Problem (authors according to Lim 1998)

At container terminals, berths are placed alongside a straight quay. Where the quay is longer, there appears the problem of allocation of berths alongside the quay. The longer the quay, the more complex the problem. There are three different types of berth design at container terminals according to Bierwirth and Meisel [1]: the fixed, continuous and hybrid ones. The traditional approach assumes fixed berths of lengths based on the expected (or average) size of the vessels at the terminal. Given the fact that the length of container ships varies in dependence on their capacity, the traditional approach does not ensure optimal utilization of the quay space. Contrary to the traditional approach, quay length can be regarded as a continuous berth without numbering. The third type is a hybrid between the previous two. The quay is divided into numbered segments of equal length (Fig. 3). Each vessel is assigned an appropriate number of segments, depending of her length overall. The safety distance between the vessels should also be taken into account.

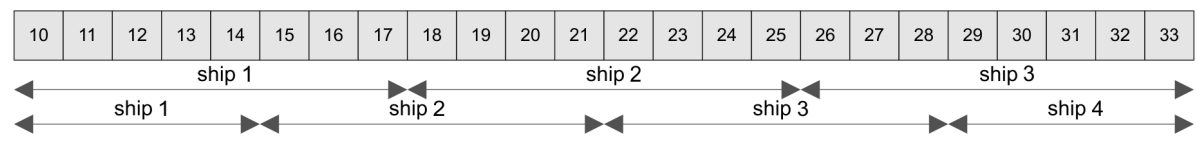

Figure 3: Quay division into berth segments

Where $b_{i}$ is the initial berth segment assigned to a vessel $i$ and $l_{i}$ the length of the vessel, then the vessel occupies exactly $b_{i}+l_{i}-1$ berth segments at the quay. For each quay segment, depth of the seawater $h_{s}$ is adjacent. Draft of the vessel is defined by 
the parameter $\tau_{i}$ as the maximum value between the arrival draft and departure draft: $\tau_{i}=\max \left(\tau_{i}^{a r r}, \tau_{i}^{d e p}\right)$. Mooring requires that the condition defined by the expression: $h_{s}>\tau_{i}+U K C$ be satisfied, where UKC is the under keel clearance as a safety distance. It should be noted that draft limitations for certain berth segments affect the assignment of other berth segments alongside the quay as well. This is shown in Fig. 4:

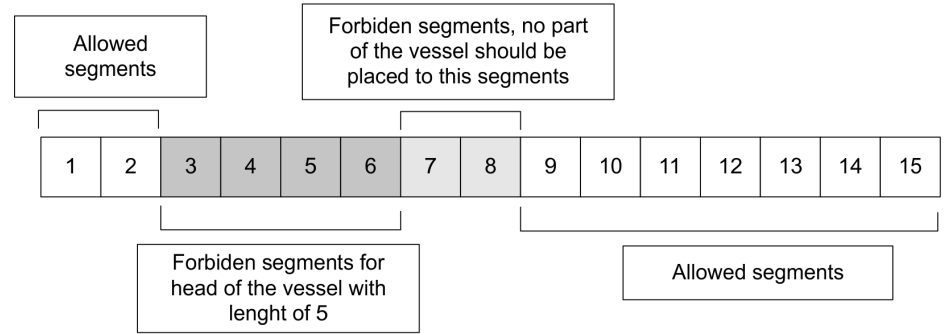

Figure 4: Allowed berth position for a vessel requiring 5 segments in length, where segments 7 and 8 have depth limitation

The above figure clearly shows that where berthing is restricted at segments 7 and 8 due to uneven sea bottom, the same restriction also applies to any other potential position of vessel's first coming portion, which is lower by one length of the vessel (positions 3-6 on the Fig. 4).

Where a group of vessels is involved, it is necessary to set up the berthing schedule, according to their estimated time of arrival (ETA) and considering the length and draft of the vessels. The departure time is calculated in relation to the processing time required for cargo operations. For berthing schedule to be created, the assignment of berth segments and corresponding time windows has to be performed. For that purpose, the mixed integer linear programming model has been developed with depth constraint. The objective is to get the optimal BAP solution with the minimum vessels total time spent at port where some depth limitation may occur, while at the same time the quay space is best utilized.

\section{Model development}

The BAP model with draft limitations has the following assumptions:

1. Vessel arrivals are stochastic but with pre-notice announcement

2. All vessels have the same priority (or not any)

3. Different sized ships arrive at port

4. Approaching and manoeuvring times are ignored

5. Preparation clearance time is integrated with the processing time

6. Processing time is fixed and unchangeable

7. There is no service resources dependency

8. Sea depth is not equal alongside the quay (stands for a limitation) 
Furthermore, the data set and decision variable definitions are required:

$V=\left\{V_{1}, V_{2}, \ldots, V_{N}\right\}$ is a set of ships, $i \in \mathbb{N}: i \leq N$, where $N$ is the total number of ships in the system. $S=\left\{S_{1}, S_{2}, \ldots, S_{L}\right\}$ is the set of berth segments $s \in \mathbb{N}: s \leq L$, where $L$ is the maximum number of segments depending on quay length. For each $i \in V$ a set of forbidden berth positions $s$ is defined $s \in S^{0}$, where $S^{0} \subset S$, so that $h_{s} \leq \max \left(\tau_{i}^{a r r}, \tau_{i}^{d e p}\right)+U K C$. The maximum value between the arrival draft $\tau^{a r r}$ and departure draft $\tau^{d e p}$ should be selected. Set $S^{0}$ has a lower bound at $\left(s-l_{i}+1\right)$. Therefore, $r_{i s}=1$ for $\forall i \in V \wedge \forall s \in S \backslash S^{0}$. The variable $y_{i j}$ determines whether the vessel $i$ is ,below" the vessel $j$ or not and the variable $z_{i j}$ determines whether the vessel $i$ is positioned „left" from the vessel $j$ or not. The variable domains are defined as follows:

$$
\begin{gathered}
y_{i j}= \begin{cases}1, & b_{j} \geq b_{i}+l_{i} \\
0, & b_{j}<b_{i}+l_{i}\end{cases} \\
z_{i j}= \begin{cases}1, & s_{j} \geq d_{i} \\
0, & s_{j}<d_{i}\end{cases} \\
r_{i s}= \begin{cases}1, & h_{s}>\max \left(\tau_{i}^{a r r}, \tau_{i}^{d e p}\right)+U K C \\
0, & h_{s} \leq \max \left(\tau_{i}^{\text {arr }}, \tau_{i}^{d e p}\right)+U K C\end{cases} \\
x_{i s}= \begin{cases}1, & \text { if head of the vessel } i \text { is assigned to segment } s \\
0, & \text { otherwise }\end{cases}
\end{gathered}
$$

The role of the binary variables $y_{i j}$ and $z_{i j}$ is to avoid overlapping of „boxes“ or vessels in the time-space diagram. The concept is derived from the „multi-row layout problem" which determines the layout of the production of service entities of different surfaces in a facility design [4]. The same is applied by Moorthy and Teo [11] in the BAP optimization (Fig. 5).
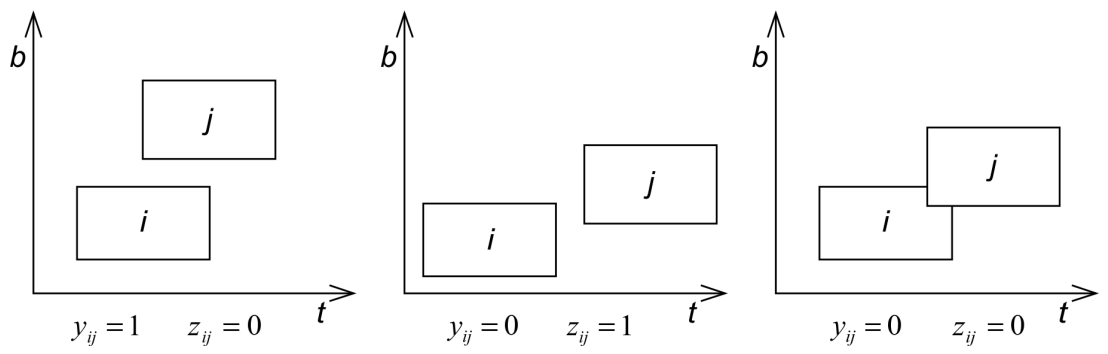

Figure 5: The relation of decision variables $y_{i j}$ and $z_{i j}$ depending on vessel's position (author according to Moorthy and Teo, 2006)

Overlapping is not allowed, which means the case where both binary variables $y$ 
and $z$ are zero should be forbidden by the model constraint.

Model notation:

\begin{tabular}{|ll|ll|}
\hline \multicolumn{2}{|c|}{ input parameters } & \multicolumn{2}{|c|}{ output variables } \\
\hline$l_{i}$ & length of vessel & $b_{i}$ & initial berth segment assigned to the vessel \\
$a_{i}$ & estimated time of vessel arrival (ETA) & $s_{i}$ & berthing time \\
$p_{i}$ & processing time of vessel at berth & $y_{i j}$ & relation of vessel pairs (vertical component) \\
$\tau_{i}$ & maximum draft of the vessel & $z_{i j}$ & relation of vessel pairs (horizontal component) \\
$h_{s}$ & sea depth at the berth segment & $w_{i}$ & waiting time for free berth \\
$h^{a r r}$ & draft on arrival & & \\
$h^{d e p}$ & draft on departure & $d_{i}$ & departure time of the vessel \\
$U K C$ & under keel clearance & $x_{i s}$ & determines initial berth segments $s$ for $i$ \\
$L$ & quay length (number of berth segments) \\
$H$ & planning horizon in time windows & $r_{i s}$ & restricted segments $s$ for $i$ \\
$M$ & big integer constant & \\
\hline
\end{tabular}

The objective function reads:

$$
\operatorname{Min} Z=\sum_{i \in V}\left(d_{i}-a_{i}\right)
$$

subject to:

$$
\begin{array}{cl}
\sum_{s=1}^{L} x_{i s}=1 & \forall i \in V \\
\sum_{s=1}^{L} s x_{i s} r_{i s}=b_{i} & \forall i \in V \\
b_{j}+M\left(1-y_{i j}\right) \geq b_{i}+l_{i} & \forall i, j \in V, i \neq j \\
s_{j}+M\left(1-z_{i j}\right) \geq d_{i} & \forall i, j \in V, i \neq j \\
y_{i j}+y_{j i}+z_{i j}+z_{j i} \geq 1 & \forall i, j \in V, i \neq j \\
s_{i}+p_{i}=d_{i} & \forall i \in V \\
a_{i}+w_{i}=s_{i} & \forall i \in V \\
s_{i} \geq a_{i} & \forall i \in V
\end{array}
$$




$$
\begin{gathered}
w_{i} \geq 0 \quad \forall i \in V \\
b_{i} \in\left[1,\left(L-l_{i}+1\right)\right]
\end{gathered}
$$

The objective function (5) is the same as in [3] but without the priority coefficient. Constraint (6) prevents that more than one initial berthing position be assigned per ship. Connection between decision variables $x_{i s}$ and $b_{i}$ is accomplished by the (7). At the same time this expression eliminates the possibility for the ship to occupy the forbidden berthing positions, since that would be the case $r_{i s}=0$ and the value of $b_{i}$ would be zero or outside the boundary specified in (15). The upper boundary of $b_{i}$ is the highest berthing position at which the heading part of the particular vessel should be positioned, so that her entire length lies alongside the quay.

The rest of constraints are taken from the [3]. The position of the vessel in the space-time diagram is determined by the (8), (9) and (10) so that there is no overlap. Note that the safety distance between the vessels should be included in the vessel size parameter. The big integer constant $M$ in (8) and (9) neutralize the constraint where there is a single axis overlap to ensure a feasible solution. No double axis overlap is allowed by (10). The relation between vessel's time of arrival, waiting, berthing and departure is set up by (11) and (12). Berthing time should fall after the time of arrival, as it is defined by (13). Finally, a lower bound of waiting time is defined by (14). The upper bound of waiting time may be added if desired.

\section{Data generation and selection}

A script has been developed for data generation including a set of 50 ships with the following parameters: length, draft, handling processing time and estimated time of arrival. It is assumed that ships of different sizes are expected at the container terminal, particularly five types of ships with different length and draft have been generated. The quay is divided into 15 segments (of approximately 50 meters each) corresponding to the total length of 750 meters. The planning horizon consists of 100 time windows. The script generates vessels data on the basis of their predefined sizes and the probability of their arrival at the port (Table 1). The handling time (processing time) and vessels' draft have been calculated using the uniform distribution function within the predefined range (min, max). The lower and upper boundary of $(a, b)$ are set up according to the length of the vessel and based on historical data. 
Table 1: The probability boundary of generated random variables

\begin{tabular}{|c|c|c|c|c|c|}
\hline \multicolumn{2}{|c|}{ Vessel } & \multicolumn{2}{c|}{$\begin{array}{c}\text { Handling time } \\
U(\mathrm{a}, \mathrm{b})\end{array}$} & \multicolumn{2}{c|}{$\begin{array}{c}\text { Draft } \\
(\mathrm{a}, \mathrm{b})\end{array}$} \\
\hline Length & Probability & $\min (\mathrm{a})$ & $\max (\mathrm{b})$ & $\min (\mathrm{a})$ & $\max (\mathrm{b})$ \\
\hline 3 & $20 \%$ & 3 & 12 & 4 & 7 \\
\hline 4 & $20 \%$ & 4 & 16 & 6 & 9 \\
\hline 5 & $30 \%$ & 4 & 18 & 8 & 12 \\
\hline 6 & $20 \%$ & 6 & 18 & 8 & 12 \\
\hline 7 & $10 \%$ & 8 & 18 & 10 & 15 \\
\hline
\end{tabular}

The vessel enters into the system upon notice of arrival. The exponential distribution of the time between vessel arrivals is used for the creation of vessels ETA by the function $\operatorname{Exp}(t)=\lambda e^{-\lambda t} t \geq 0$ with the rate of arrival $\lambda=3$ (see Fig.6).

Time interval distribution

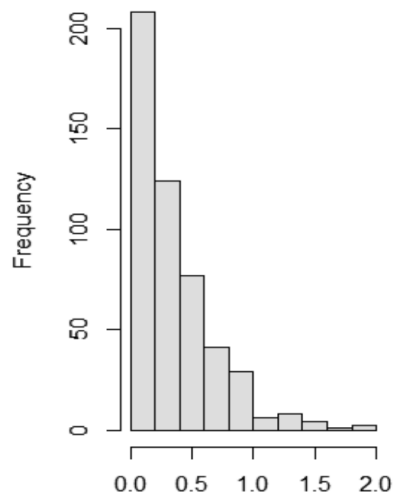

Arrival rate

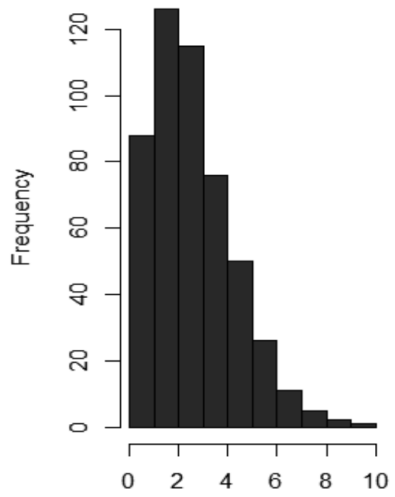

Figure 6: Frequency of vessel's arrival with average rate $\lambda=3$

Vessels are grouped into groups of five, with the total of 10 groups created. Each group of vessels has been developed two BAP solution scenarios. In the first scenario, no limit is provided, thus the constraints (6) and (7) are removed from the model. In the second scenario, certain limitation in depth is set up, particularly along berth segments 1, 2 and 3 where depth of the sea is limited to 11 meters. For the generation of vessels data, the R programming statistical tool is used. The model is coded and running in the LINGO 12.0 optimization language. The results are presented in the next section. 


\section{Optimization results and analysis}

Optimization results representing the solution of the BAP problem are shown in Table 2. The selected solutions are also shown in Figure 7.

It may be noted that the optimization function values have been changed for groups 3,5 and 8 , where the value of $Z$ is increased as a consequence of less available berth segments and larger ships arrivals. Therefore, some of them should be routed to the anchorage, thus producing waiting time and increasing vessel's total service time at port.

Looking at the table for cases where there has been no change in the value of the objective function, one can note that berth positions are re-arranged so that the draft constraint does not jeopardize vessels mooring alongside the quay. That is the case, for instance, with vessel 5 - changed berth position from $b=2$ to $b=10$, vessel 43 changed from $b=1$ to $b=8$ and vessel 47 from $b=1$ to $b=9$. Note that the depth alongside berth segments 1, 2 and 3 was limited to 11 meters and all the vessels involved have $\tau \geq 11$, and therefore the condition $b \geq 4$ must be satisfied.

The principle showing how the model works can be seen in the graphical presentation (Fig.7). Let us look at the group 3 (vessels 11-15). An optimal berthing schedule without draft limitation requires that vessel no. 14 should wait 3 time windows to be berthed at $29^{\text {th }}$ immediately after vessel no.13 has left berth segments $1-3$. There is no better solution because two large vessels, 12 and 14, overlap in time. Where depth limitation is included, both vessels have draft over the limit set up for berth positions $1-3$, and thus they should not be accommodated there. The picture clearly shows that vessel no. 14 is shifted above the limit area (coloured grey) but only after vessel no. 12 has left the berths. The effect is a longer waiting time at the anchorage for the vessel, which explains higher value of the objective function. 
Table 2: Results of BAP with and without draft limitation

\begin{tabular}{|c|c|c|c|c|c|c|c|c|c|c|c|c|}
\hline & & & & & \multicolumn{4}{|c|}{ no depth constraint } & \multicolumn{4}{|c|}{ with depth constraint } \\
\hline$i$ & $l$ & $p$ & $\tau$ & $a$ & $b$ & $w$ & $s$ & $d$ & $b$ & $w$ & $s$ & $d$ \\
\hline 1 & 3 & 4 & 4 & 5 & 1 & 0 & 5 & 9 & 1 & 0 & 5 & 9 \\
\hline 2 & 5 & 13 & 10 & 17 & 4 & 0 & 17 & 30 & 1 & 0 & 17 & 30 \\
\hline 3 & 5 & 12 & 10 & 23 & 9 & 0 & 23 & 35 & 6 & 0 & 23 & 35 \\
\hline 4 & 4 & 8 & 7 & 38 & 2 & 0 & 38 & 46 & 1 & 0 & 38 & 46 \\
\hline 5 & 6 & 15 & 11 & 55 & 2 & 0 & 55 & 70 & 10 & 0 & 55 & 70 \\
\hline & & & & & \multicolumn{4}{|c|}{$\mathrm{Z}=52$} & \multicolumn{4}{|c|}{$Z=52$} \\
\hline 6 & 5 & 10 & 10 & 4 & 1 & 0 & 4 & 14 & 1 & 0 & 4 & 14 \\
\hline 7 & 5 & 10 & 10 & 5 & 6 & 0 & 5 & 15 & 6 & 0 & 5 & 15 \\
\hline 8 & 5 & 13 & 10 & 14 & 11 & 0 & 14 & 27 & 11 & 0 & 14 & 27 \\
\hline 9 & 5 & 11 & 10 & 27 & 11 & 0 & 27 & 38 & 11 & 0 & 27 & 38 \\
\hline 10 & 3 & 4 & 4 & 33 & 4 & 0 & 33 & 37 & 4 & 0 & 33 & 37 \\
\hline & & & & & \multicolumn{4}{|c|}{$\mathrm{Z}=48$} & \multicolumn{4}{|c|}{$Z=48$} \\
\hline 11 & 5 & 11 & 10 & 10 & 1 & 0 & 10 & 21 & 1 & 0 & 10 & 21 \\
\hline 12 & 7 & 17 & 15 & 16 & 8 & 0 & 16 & 33 & 9 & 0 & 16 & 33 \\
\hline 13 & 3 & 4 & 4 & 25 & 1 & 0 & 25 & 29 & 1 & 0 & 25 & 29 \\
\hline 14 & 7 & 18 & 15 & 26 & 1 & 3 & 29 & 47 & 9 & 7 & 33 & 51 \\
\hline 15 & 3 & 3 & 4 & 35 & 12 & 0 & 35 & 38 & 5 & 0 & 35 & 38 \\
\hline & & & & & \multicolumn{4}{|c|}{$\mathrm{Z}=56$} & \multicolumn{4}{|c|}{$Z=60$} \\
\hline 16 & 7 & 18 & 15 & 22 & 9 & 0 & 22 & 40 & 4 & 0 & 22 & 40 \\
\hline 17 & 5 & 11 & 10 & 25 & 1 & 0 & 25 & 36 & 11 & 0 & 25 & 36 \\
\hline 18 & 6 & 15 & 11 & 48 & 8 & 0 & 48 & 63 & 10 & 0 & 48 & 63 \\
\hline 19 & 3 & 4 & 4 & 51 & 3 & 0 & 51 & 55 & 1 & 0 & 51 & 55 \\
\hline 20 & 4 & 9 & 7 & 60 & 4 & 0 & 60 & 69 & 1 & 0 & 60 & 69 \\
\hline & & & & & \multicolumn{4}{|c|}{$\mathrm{Z}=\mathbf{5 7}$} & \multicolumn{4}{|c|}{$\mathrm{Z}=\mathbf{5 7}$} \\
\hline 21 & 5 & 11 & 10 & 12 & 1 & 0 & 12 & 23 & 1 & 0 & 12 & 23 \\
\hline 22 & 5 & 12 & 10 & 21 & 8 & 0 & 21 & 33 & 8 & 0 & 21 & 33 \\
\hline 23 & 4 & 9 & 7 & 41 & 1 & 0 & 41 & 50 & 1 & 0 & 41 & 50 \\
\hline 24 & 4 & 8 & 7 & 45 & 5 & 0 & 45 & 53 & 5 & 0 & 45 & 53 \\
\hline 25 & 3 & 3 & 4 & 47 & 9 & 0 & 47 & 50 & 9 & 0 & 47 & 50 \\
\hline & & & & & \multicolumn{4}{|c|}{$\mathrm{Z}=\mathbf{4 3}$} & \multicolumn{4}{|c|}{$Z=43$} \\
\hline 26 & 7 & 17 & 15 & 2 & 5 & 0 & 2 & 19 & 7 & 0 & 2 & 19 \\
\hline 27 & 4 & 9 & 7 & 5 & 1 & 0 & 5 & 14 & 1 & 0 & 5 & 14 \\
\hline 28 & 6 & 17 & 12 & 53 & 10 & 0 & 53 & 70 & 4 & 0 & 53 & 70 \\
\hline 29 & 5 & 13 & 11 & 57 & 5 & 0 & 57 & 70 & 11 & 0 & 57 & 70 \\
\hline 30 & 5 & 11 & 10 & 63 & 6 & 7 & 70 & 81 & 1 & 7 & 70 & 81 \\
\hline & & & & & & & & & & & & \\
\hline 31 & 5 & 13 & 11 & 1 & 1 & 0 & 1 & 14 & 4 & 0 & 1 & 14 \\
\hline 32 & 5 & 11 & 10 & 21 & 1 & 0 & 21 & 32 & 1 & 0 & 21 & 32 \\
\hline 33 & 3 & 4 & 4 & 51 & 1 & 0 & 51 & 55 & 1 & 0 & 51 & 55 \\
\hline 34 & 6 & 16 & 11 & 60 & 1 & 0 & 60 & 76 & 4 & 0 & 60 & 76 \\
\hline 35 & 7 & 17 & 15 & 66 & 9 & 0 & 66 & 83 & 4 & 10 & 76 & 93 \\
\hline & & & & & & & & & & & & \\
\hline 36 & 7 & 17 & 15 & 16 & 7 & 0 & 16 & 33 & 9 & 0 & 16 & 33 \\
\hline 37 & 6 & 15 & 11 & 20 & 1 & 0 & 20 & 35 & 4 & 20 & 40 & 55 \\
\hline 38 & 6 & 15 & 11 & 29 & 1 & 6 & 35 & 50 & 10 & 4 & 33 & 48 \\
\hline 39 & 5 & 10 & 10 & 30 & 11 & 3 & 33 & 43 & 1 & 0 & 30 & 40 \\
\hline 40 & 5 & 11 & 10 & 36 & 7 & 7 & 43 & 54 & 10 & 12 & 48 & 59 \\
\hline & & & & & & & & & & & & \\
\hline 41 & 4 & 9 & 7 & 16 & 1 & 0 & 16 & 25 & 10 & 0 & 16 & 25 \\
\hline 42 & 6 & 15 & 11 & 22 & 5 & 0 & 22 & 37 & 4 & 0 & 22 & 37 \\
\hline 43 & 7 & 18 & 15 & 37 & 1 & 0 & 37 & 55 & 8 & 0 & 37 & 55 \\
\hline 44 & 3 & 3 & 4 & 38 & 13 & 0 & 38 & 41 & 1 & 0 & 38 & 41 \\
\hline 45 & 5 & 11 & 10 & 46 & 11 & 0 & 46 & 57 & 1 & 0 & 46 & 57 \\
\hline & & & & & & & & & & & & \\
\hline 46 & 4 & 7 & 7 & 4 & 1 & 0 & 4 & 11 & 1 & 0 & 4 & 11 \\
\hline 47 & 6 & 15 & 11 & 16 & 1 & 0 & 16 & 31 & 9 & 0 & 16 & 31 \\
\hline 48 & 5 & 13 & 10 & 26 & 7 & 0 & 26 & 39 & 4 & 0 & 26 & 39 \\
\hline 49 & 3 & 5 & 5 & 38 & 1 & 0 & 38 & 43 & 1 & 0 & 38 & 43 \\
\hline 50 & 5 & 13 & 10 & 54 & 3 & 0 & 54 & 67 & 1 & 0 & 54 & 67 \\
\hline & & & & & & & & & & & & \\
\hline
\end{tabular}



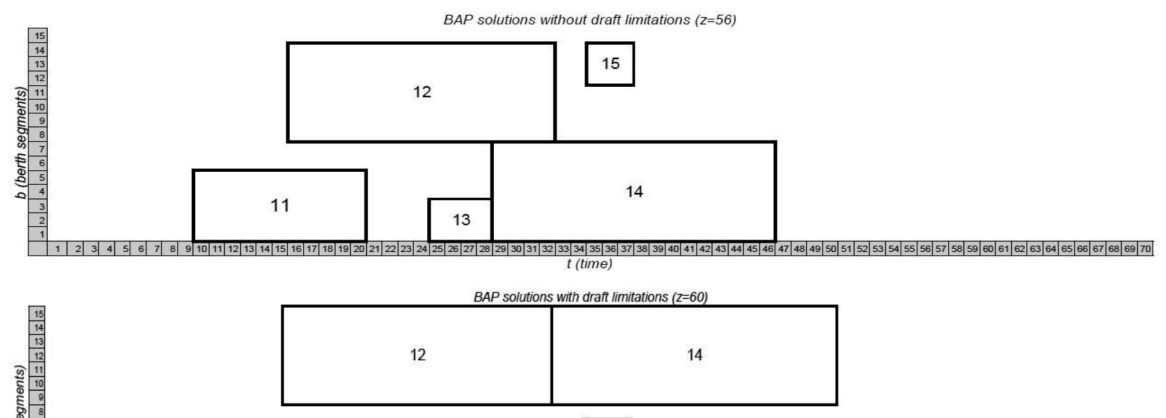

\section{5}

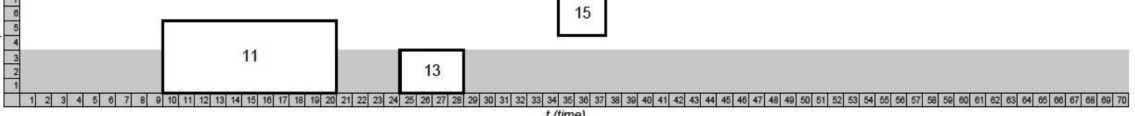
$t$ (time)
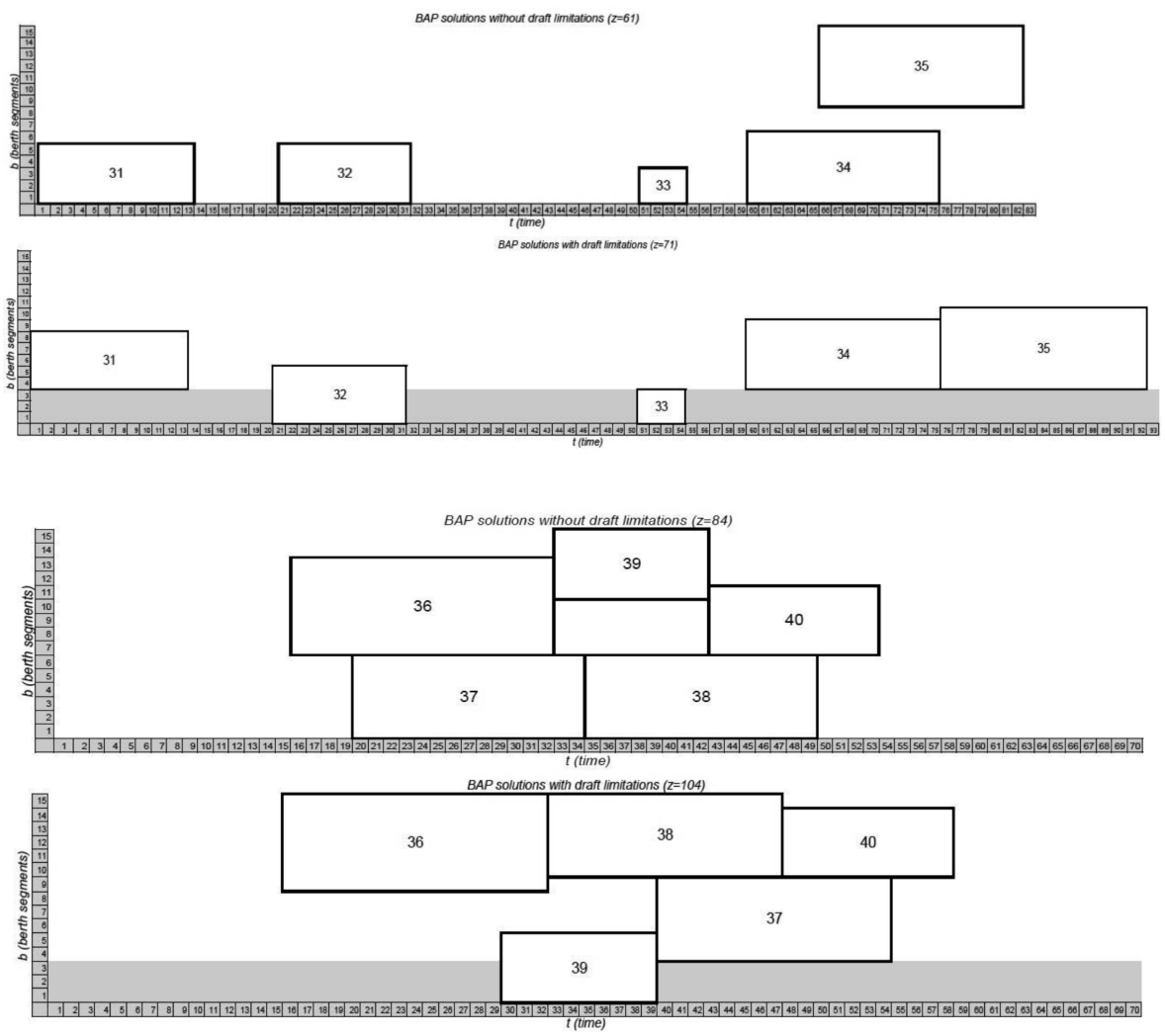

Figure 7: Graphical presentation of the selected results with and without draft limitation 
A similar situation can be seen in the group number 7, where vessels no. 31 and 34 are moved to the first unrestricted quay area which is berth segment no.4. Again, ship length does not allow for vessels no.34 and 35 to be docked at the same time because the total length of those two vessels is 13 , and the total unrestricted area consists of 12 berth segments only.

The last example is about the group 8 (vessels from 36 to 40). This group has the highest density of vessel arrivals among the created groups. Three vessels have draft restrictions, no.36, 37 and 38 . In order to satisfy the draft constraints, their berthing order has to be rearranged. This rearrangement led to a significant increase in waiting time for vessel no.37 $(w=10)$, however, that is the price for the total optimization. To avoid cases with only one ship bearing the overall price of optimization, the upper waiting boundary constraint may be inserted into the model presented in section three.

\section{Conclusion}

The model presented in this paper may solve the berth allocation problem where a draft restriction is applied caused by shortcomings in the sea-depth alongside the quay. The objective of the optimization, the minimum overall vessels service time, can also be achieved in that restricted environment. Model testing has been performed with a small group of ships with random arrivals where it is easy to follow the set up objective and compare the results with and without a draft limit. In all 10 groups, with the total of 50 vessels, an optimal solution is found and in all cases berths are assigned to vessels taking into account the draft restrictions.

However, the presented model works together with certain assumptions which are elaborated beforehand. The most important one is the processing time that may vary in dependence on the available resources and cargo distribution on board. Thus, the purpose of this work is to show the ability to create and to adapt the BAP according to different environment and different terminal requirements rather than to develop a fully featured standalone model. 


\section{References}

1. Bierwirth, C. \& Meisel, F. (2010) A survey of berth allocation and quay crane scheduling problems in container terminals. European Journal of Operational Research. 202 (3), pp. 615-627.

2. Cordeau, J.-F., Laporte, G., Legato, P. \& Moccia, L. (2005) Models and Tabu Search Heuristics for the Berth-Allocation Problem. Transportation Science. 39 (4), pp. 526-538.

3. Guan, Y. \& Cheung, R.K. (2004) The berth allocation problem: models and solution methods. OR Spectrum. 26 (1), pp. 75-92.

4. Heragu, S.S. (2008) Facilities Design. CRC Press.

5. Imai, A., Nishimura, E., Hattori, M. \& Papadimitriou, S. (2007a) Berth allocation at indented berths for mega-containerships. European Journal of Operational Research. 179 (2), pp. 579-593.

6. Imai, A., Nishimura, E. \& Papadimitriou, S. (2001) The dynamic berth allocation problem for a container port. Transportation Research Part B: Methodological. 35 (4), pp. 401-417.

7. Imai, A., Sun, X., Nishimura, E. \& Papadimitriou, S. (2005) Berth allocation in a container port: using a continuous location space approach. Transportation Research Part B: Methodological. 39 (3), pp. 199-221.

8. Imai, A., Zhang, J.-T., Nishimura, E. \& Papadimitriou, S. (2007b) The Berth Allocation Problem with Service Time and Delay Time Objectives. Maritime Economics \& Logistics. 9 (4), pp. 269-290.

9. Kim, K.H. \& Moon, K.C. (2003) Berth scheduling by simulated annealing. Transportation Research Part B: Methodological. 37 (6), pp. 541-560.

10. Lim, A. (1998) The berth planning problem. Operations Research Letters. 22 (2-3), pp. 105-110.

11. Moorthy, R. \& Teo, C.-P. (2006) Berth management in container terminal: the template design problem. OR Spectrum. 28 (4), pp. 495-518.

12. Nishimura, E., Imai, A. \& Papadimitriou, S. (2001) Berth allocation planning in the public berth system by genetic algorithms. European Journal of Operational Research. 131 (2), pp. 282-292.

13. Xu, D., Li, C.-L. \& Leung, J.Y.-T. (2012) Berth allocation with time-dependent physical limitations on vessels. European Journal of Operational Research. 216 (1), pp. 47-56.

14. Meisel, F. (2009) Seaside Operations Planning in Container Terminals. Springer. 
Neven Grubišić, Siniša Vilke, Mate Barić

\section{Doprinos rješavanju problema dodjele veza kod ograničenja gaza}

\section{Sažetak}

Modeli za dodjeljivanje veza brodu pomažu rješavanju logističkih problema na kontejnerskim terminalima i predstavljaju važan alat za donošenje odluka. To je posebno značajno u slučajevima kada se, zbog složenosti sustava i intenziteta dolazaka brodova, problem ne može riješiti empirijski. Drugi problem predstavljaju moguća infrastrukturna ograničenja ili nedostatak opreme gdje se zahtijeva visoka razina učinkovitosti postojećih komponenti sustava. U ovom radu autori stavljaju u središte ograničenje gaza, odnosno dubine mora, koje može postojati uzduž pristana. Postojeća istraživanja u ovom području uzeta su u razmatranje i model za optimizaciju dodjele vezova je nadograđen da bi se ispunio uvjet postavljenog ograničenja. Razvijeni model je testiran za slučajeve sa i bez ograničenja dubine uz pristan. U svrhu vrednovanja dobivenih rezultata, generirani su slučajni dolasci brodova kao i njihove tehničke specifikacije.

Ključne riječi: problem dodjele veza, ograničenje gaza, optimizacija kontejnerskog terminal, lučka logistika. 